\title{
INVESTIGATING "OTHERING" IN VISUAL ARTS SPACES OF LEARNING
}

\author{
Monique Biscombe \\ Stellenbosch University \\ biscombemonique@gmail.com
}

Stephané Conradie

Stellenbosch University

stephaneedithconradie@gmail.com

\section{Elmarie Costandius}

Stellenbosch University

elmarie@sun.ac.za

Neeske Alexander

Stellenbosch University

neeskealexander@gmail.com

\section{ABSTRACT}

In the political, social, cultural and economic context of South Africa, higher education spaces provide fertile ground for social research. This case study explored "othered" identities in the Department of Visual Arts of Stellenbosch University. Interviews with students and lecturers revealed interesting and controversial aspects in terms of their experiences in the Department of Visual Arts. Theoretical perspectives such as "othering", symbolic racism, the racialised body and visual art theory were used to interpret these experiences. It was found that "othering" because of indirect racism and language or economic circumstances affects students' creative expression. Causes of "othering" experiences should be investigated in order to promote necessary transformation within the visual arts and within higher education institutions.

Keywords: othering; racialised body; transformation; visual arts; language

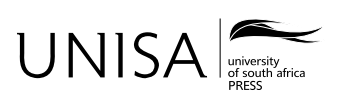

Education as Change www.educationaschange.co.za

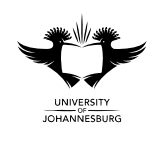

DOI: http://dx.doi.org/10.17159/1947-9417/2017/1070 Print ISSN 1682-3206 | Online 1947-9417

(C) The Authors 2017 


\section{INTRODUCTION}

Higher education institutions represent critical spaces for learning in which dialogues between people from diverse backgrounds are encouraged. These interactions should build environments where difference is recognised. This includes recognising the categorical differences we project onto those who are "other" than ourselves in order to make sense of the difference we experience (Oloyede 2009, 427). Ideally, acceptance and celebration of difference should be evident in higher education institutions. The promotion of an identity that embraces multiple loyalties instead of producing conflict could lessen the gap between members of different cultural and racial backgrounds (Costandius and Rosochacki 2012).

In universities that were historically predominantly white, opportunities now exist for black students to enter. Although many of these institutions are making progress with regard to a numerical representation of black students and staff, a lack of "meaningful intergroup interaction" still exists between members of different racial groups (Oloyede 2009). Stellenbosch University's position presents a twofold dilemma, because the demographic representation does not reflect that of South Africa and because the creation of inclusive environments for all students remains difficult. Many black students simply do not want to enter a place where their difference may set them apart from the rest of the largely racially and culturally homogenous student community (Costandius and Rosochacki 2012).

Stellenbosch University, designated as a race-specific ("white" Afrikaner) institution during apartheid, played a critical role in the cultivation of South Africa's painful history. The university supplied the government with more than one of the National Party's ministers. Stellenbosch University promoted a culture of "white supremacy" during apartheid and this subtly continues in new forms present on campus (Odendaal 2012).

This study aimed to explore "othered" identities within a South African political, social, cultural and economic context and, more specifically, the related challenges that may exist within higher education spaces of learning. The Department of Visual Arts at Stellenbosch University was used as a case study in order to analyse the ways in which students experience "othering". Personal biographical experiences were collected from lecturers and students. Theoretical perspectives such as "othering", symbolic racism, the racialised body and visual art theory were useful for interpreting these experiences. Excerpts from the interviews conducted with participants are presented, followed by a discussion of the data.

\section{THEORETICAL PERSPECTIVES}

\section{Othering}

This case study examined instances of "othering" experienced by marginalised identities within visual arts spaces of learning. It is therefore important to expand on the 
concepts of the "other" and "othering". While varying viewpoints of "othering" exist (for example the "fascinating other") we chose the specific frame of "othering" and the "other" that is presented below. This frame is mainly based on the readings of Spivak (1985) and Jensen (2009). Framing the "other" as inferior, subordinate and unable to access education is relevant within the context of higher education institutions because it is part of the racialisation process that prevents transformation.

The concept of the "other" is complex in its definition. First, humanity is divided into two groups: one embodying the norms, whose identity is valued, and another defined by its faults, "devalued and susceptible to discrimination" (Staszak 2008, 1). Second, as presented by Gillespie $(2007,2)$,

the representation of the other is deeply entwined with the representation of self...[O]thering occurs when Self represents Other in terms of what Self is not (and in terms of what self does not want to be) in a way that is "self-aggrandizing".

For this reason, the "other" exists because of binaries in relation to the self. This concept relates to a Hegelian heritage (1947) in which the juxtaposition with the "other" composes the self (Jensen 2009).

"Othering" describes a multidimensional process that touches upon "several different power asymmetries" (Jensen 2009, 10). Postcolonial writer Gayatri Chakravorty Spivak (1985) was the first to use the notion of "othering" in a way that was systematic (Jensen 2009, 7). By investigating representations of history, she identified three forms of "othering".

The first form of "othering" involves an awareness of who holds the power. Those who are powerful produce the "other" as subordinate (Jensen 2009). The second form views the "other" as "pathological and morally inferior". Those classified as "other" are considered "uncivilised, uneducated and barbaric" in nature (Jensen 2009, 10). The third form of "othering" involves denying the "other" access to knowledge and technology. This process establishes a "manipulative pedagogy" that produces an unnatural difference between native and master. This power imbalance allows those with power to maintain that power (Jensen 2009, 10). The "other" is therefore understood as being an inferior "other" and not a fascinating "other" (Jensen 2009). "Othering" plays a key role in racialisation, because it defines bodies as "other" according to race.

In the past, discourses of racialisation were used by the apartheid state to develop institutions and processes devoted to producing and transmitting knowledge that would support the apartheid agenda (Ratele and Shefer 2003). Each body affected by the discourses imposed by the apartheid state continues to be reactive to the "other" or defined against it. A symbolic agreement is reached where "harmony" between the self and the "other" exists and where the "other" does not challenge the notions of self set up

1 "The insistence of the specificity of othering of ethnic minorities, because it relies on racist assumptions about 'visibly different minorities', may include physical abuse" (Garland and Chakraborti 2006, 150-177). 
by the dominating body (Bignall 2008, 131). Similarly, students who see themselves as different may feel that it is better for them to be assimilated into their environment. This possibly prevents further isolation by accepting dominant ways of thinking and being. Some students, however, may choose to live in the isolation they experience because of their difference. Students who are different from the majority may experience "othering" due to a lack of community in which they can "fit in" and find accountability.

\section{Symbolic racism, symbolic power and symbolic violence}

David Sears (1998 cited in Ratele and Duncan 2003) developed the term "symbolic racism" in order to describe and articulate racism and its development within the USA. He argues that traditional forms of racial discrimination are no longer obvious and visible. Contemporary forms of discrimination could consist of more subtle plays of power through muted violence. "Symbolic racism" is defined as emerging forms of prejudice and discrimination. This includes denying the existing patterns of racial inequalities, resentment of redress and antagonism towards demands for removing racism in society (Ratele and Duncan 2003). Contemporary racial discrimination can therefore be identified as "symbolic racism". "Symbolic racism" may be exercised outwardly through various plays of power and subtle violence. Bourdieu's (1991) development of the two concepts of "symbolic power" and "symbolic violence" may make valuable contributions to our understanding of "symbolic racism".

"Symbolic power" has two distinct features. First, it does not reside in systems, but is defined in and through a given relationship between those exercising power and those submitting to it. Legitimacy and belief in words and slogans are created. This belief is produced and reproduced while maintaining or subverting social order. Second, "symbolic power" is a subordinated power that is a "transformed, misrecognizable, transfigured and legitimated form of the other forms of power" (Bourdieu 1991, 170). The process of "symbolic violence" becomes possible through "symbolic power". An imbalance of power is cultivated that perpetuates the "other" as inferior by those exercising this power.

"Symbolic violence" refers to violence that is not physical or visible, but exists on a subtle level. This "violence" is felt on an unconscious level through body language, words and actions. It is difficult to pinpoint, but it remains deeply ingrained in individuals, without their awareness of it (Bourdieu 1991). "Symbolic violence" is the natural progression from "symbolic power" once the "other" eschews words, slogans and norms that are created and accepted by the dominant group (Bourdieu 1991). Therefore, "symbolic racism" is assisted by the presence of "symbolic power" and "symbolic violence".

As the "symbolic racism" experienced by students may very well be more subtle and less confrontational, the use of the terms "symbolic power and violence" could give definition and lucidity to how this experience is perpetuated. Students of 
colour are no longer barred from entering a previously whites-only university like Stellenbosch University, but they still feel "othered" and isolated from the community. The discrimination is obviously subtle. By describing how "symbolic racism" may be perpetuated through and assisted by "symbolic power and violence" we may more fully understand the levels of racism experienced by students.

\section{The racialised body}

The "body" in this study is viewed as a vehicle for the development of discourse. The body carries historical definitions that place it within a racial group. In spite of many anti-racial policies in South Africa, the body continues to be racialised within society and spaces of learning. Miles (1989 cited in Ratele and Shefer 2003, 94) uses the term "racialisation" to denote "a dialectical process by which meaning is attributed to particular features of the body in order to construct difference and legitimise inequality on the basis of "race"'.

During apartheid, the body was inscribed with discourses that still affect the way we categorise bodies today. Certain bodies were inscribed with privilege, while others were denied this privilege. Race was used to create a hierarchy of privilege. In post-apartheid South Africa, those who benefitted and continue to benefit directly or indirectly from this hierarchy should contend with the responsibility of the social capital they gained. Those who still suffer under continuing oppression should search for ways to reaffirm their identities. They should do this without adapting to the societal norms that sought to undermine them (Bignall 2008). The divide between bodies that benefitted from apartheid and bodies that suffered under apartheid creates significantly different experiences.

Difference is primarily emphasised through the racialisation of certain individuals and groups. The ideologies of colonisation and apartheid inform the binaries of this difference. Certain individuals benefit from a university's cultural and economic setting because they are part of a "white supremacy". Subtle alienation and prejudices experienced by those who are not part of this "white supremacy" exist within spaces of learning. This oppression continues because of a lack of awareness of the urgency for transformation. Teaching and learning are often composed without direct or blatant reference to race. Yet teaching and learning practices based on a "white" system hold direct implications for black ${ }^{2}$ students. Transformation can therefore be stunted through hidden modes of communication (Jansen 2004, 11).

2 We use "black" here to include all those students who do not fall under the categorisation of white, acknowledging that this categorisation is a direct implication of apartheid laws. Disregarding this categorisation, however, would be to ignore the colossal impact that these laws of categorisation still have in South African society today (Seekings 2008). 


\section{Visual arts and "othering"}

In the Department of Visual Arts, the outcomes reflected in the University's mission statement (Stellenbosch University 2011) are not effectively realised. These outcomes emphasise respect for diversity and difference. Knowledge applied for the mutual benefit of the community is also emphasised. This mission statement is not practically visible in students' work and the racial representation of the student body. The lack of racial diversity may contribute to the absence of dialogues centred on the complex social and political challenges South Africans face. A correlation can be drawn between the absence of social consciousness and the comfort of privilege that many of the students and staff members experience (Costandius and Rosochacki 2012).

A "blindness" towards difference may also be evident in the Department of Visual Arts. Jansen (2004, 117-128) states that a "colour blind" approach to curriculum is not a solution and that it is used to maintain the status quo of "white" superiority. Lecturers may claim that they "see students and not colour". Jansen $(2004,117-128)$ critiques this by saying "that is exactly where the problem lies: a lack of consciousness, very often, of the ways in which schools are organized and teaching conveyed that in fact hold direct consequences for learners, identity and transformation".

Prejudice and alienation may be perpetuated by the tradition of Western art. Traditions hold habitually established aesthetic styles that are thought to be appealing and beautiful and contribute to permanent value in a specific culture (Menon 2003). Traditions are recognised by academics, critics and members of the public because of the stability they attribute to cultures. In the past, traditions have been categorised in a teleological way - valuing some cultural traditions above others. In the West these traditions have come to acquire the title "classical". Menon (2003) argues that this has a particular relevance to the arts, because certain styles and disciplines are attributed to the geniuses of a race - the European race. She goes on to say that styles such as painting, music and dance within a Western rhetoric are seen to be "true" standards of artistic genius. Western artistic forms have been used as a foundation on which other artistic modes are judged as inferior (Menon 2003) and arts curricula are dominated by works of Western culture (Giroux 1992). "Othering" may therefore be present in the way artworks are judged and valued.

An example is when a white lecturer is educated in a Western dominated system and shown only Western art as examples of good art. A perception is formed of what is good and when the lecturer evaluates an artwork that is influenced by African art, it could be subconsciously considered of a lesser standard. The students coming into the Visual Arts Department are mostly white students. The students of colour are in the minority and often feel uncomfortable talking and producing work about their own cultural and social experiences. The power dynamic in this instance is emphasised when topics relating to students of colour's social and cultural backgrounds are discussed in class by white lecturers and students. Students in the minority group may feel that they do not have a voice to speak about their own experiences. If there were more students of 
colour in each class and they felt like they had the freedom to discuss their experiences and consequently produce work about it, there might be an opportunity to challenge even their white lecturer into reevaluating the lens as well as the gaze from which the lecturer is teaching and evaluating a student's work.

\section{RESEARCH METHODOLOGY}

A qualitative research design was employed for this case study. The social and cultural context of the research problem lends itself to qualitative research, because it focuses primarily on the value of processes and entities that cannot be identified by merely examining or measuring data collected (Denzin and Lincoln 2008). In terms of this design, researchers are required to acknowledge not only their own perspective but also the many voices that emerge during the research process. Researchers should adopt a reflective attitude towards inquiry that aims to gain a holistic understanding of the research subject. Qualitative research is useful for investigating social, educational and political imbalances that will inevitably be present within this particular field of inquiry.

For this study we worked with an interpretative lens, as recommended by Klein and Meyers (1999). An interpretive lens on knowledge requires reflection on how data are socially constructed and a sensitivity to contradictions, interpretations, distortions and biases of the narratives generated (Klein and Meyers 1999). We used a case study research design (Creswell 2003; Denscombe 2003) aimed at exploring and providing an in-depth investigation of "othered" bodies in visual arts spaces of learning.

This research started with a masters study that was conducted by one of the researchers, who is now a PhD student. Further data were collected after the masters research was completed and then four researchers collaboratively worked on the article. Involved in the study were two coloured, one $\mathrm{PhD}$ student and one part-time lecturer, and two white, a lecturer and one masters student, researchers. The coloured lecturer studied at the same department for six years and taught for one year, and the white lecturer was teaching at the department for ten years. The $\mathrm{PhD}$ student studied at the department for seven years and the masters student for one year.

Purposive sampling was used. Specific students were chosen because of their particular position in the department. This could be considered as bias because it relied on the judgement of the researchers. However, three researchers were involved in the selection which reduced the chance of bias to a certain extent. The original participants were chosen by the masters student and the next phase of interviewees were collaboratively chosen by three of the researchers (two coloured and one white). The reason why we included two coloured persons to make the choice was that they could associate more with feelings of being "othered" in this context and therefore could probably make a better selection. Coloured and white researchers were included to enable more objective analysis of the data. 
Data were collected from observation and interviews. From 2012 to 2015, several interviews were conducted with 12 participants from the Department of Visual Arts. The participants, who involved eight students and four lecturers in the Department of Visual Arts at Stellenbosch University, were interviewed in an environment that was "safe" and comfortable. This means that the interviews took place in a quiet environment behind closed doors, where discussions could not be overheard and where participants could speak freely without fear of judgement or victimisation. The safe space provided equal opportunity to voice their opinions, which at times were brutally honest and controversial. The information gathered from the interviews provided in-depth insights into the experiences of the participants, as maintained by Yin (2009).

Two rounds of interviews were conducted. The participants from the initial selection consisted of two black, four coloured and two white students, and one black ${ }^{3}$ and three white lecturers. The second round of participants were six students from the first sample. We asked a person from outside the university to do the second round of interviews because we wanted to reduce the bias from the researchers.

Inductive content analysis was utilised for analysing the data. This research approach allows for the identification of patterns and themes within the data collected. All the data were read by the researchers. Themes were compared and then we collaboratively decided what to use. All black and coloured respondents felt that they were "othered" in some way. One white respondent felt sympathy with black and coloured students for being "othered", and the other white participants did not feel that they were "othered". The lens that was used to analyse the data was both how students perceive themselves as "other" and how dominant culture sees them as "other".

\section{FINDINGS AND DISCUSSION OF THE INVESTIGATIONS}

In the following section the data from the interviews are presented. It is divided into four different thematic groups. At times participants' responses stretched over more than one theme. It is therefore important to read this section as a whole and to consider the interwoven nature of themes within qualitative research. The themes are governed by an overarching notion of "othering", but are discussed in four different sub-themes, namely symbolic racism, language and culture, economic and social circumstances and, lastly, visual hegemony.

\section{Symbolic racism}

In the Department of Visual Arts, racial discrimination can be described as "symbolic racism", as termed by De la Rey and Duncan $(2003,48)$. While the department does

3 Only one black lecturer was chosen because he is the only lecturer, apart from the researcher, who is black or coloured in the department. 
not present explicit racism, indirect racism seems prevalent. Students who are directly affected by this indirect racial discrimination recalled their experiences.

Student S4 remembered the first day at the department as follows:

...I was looking around and like - Where the hell are all the black people? [laughs] Oh my goodness, did someone get stuck in traffic? What is happening here?...You just know, from that day, I just knew, no one needed to tell me...it's just something is wrong, something is very, very wrong. It's a university, I understand if it's maybe a high school, maybe the parents can't afford to pay or something, but this is a university, where people can get funding. And you often wonder, like I really, really wondered, did I get in here by merit or because they just wanted their numbers to do something? And I am pretty sure it's the second one, like honestly.

Student S3 mentioned the hidden nature of racism:

But I've never been called the " $k$ " word, but [it] doesn't mean if someone doesn't call you that then they're not racist or whatever. Racism can come in different ways, you know.

Student S5 mentioned that coloured people would usually sit together. She also mentioned that her accent was mocked:

People will like joke about uhm coloured people's accents and then it's like oh it's fine to joke about it.

Student S5 recounted an incident which demonstrates the symbolic racism involving resentment of redress:

This girl in my class she, we were talking about the language policy, and she is like "No, this English business is annoying now. You English people, why don't you just go to [name of English university] or something? You knew that this place was upper class. Why do you want to come here... why do you want to come here and change it? Just go to wherever and go tell them, you know, to teach in English or to teach in new languages, but don't come here and tell us to change [from] Afrikaans".

Often racism also has to do with maintaining power. Power, as Student S1 explained it, is about maintaining privilege and comfort.

They [white students] are comfortable, this is the safe zone for them. It is like home away from home basically. Everything gets done the way that they're use to [it] being done.

Student S1 continued to say that:

No one will openly say it like "I am a little racist at school, I have been raised that way". Everyone is afraid to say [it]. Let's just be honest about it...for my first year and coming to res[idence], like and you ask me who do I want a room with. I am going to choose a black girl, and I am not even going to lie about that. I am going to, because I am comfortable. But I think people....are just ignorant about it. 
This student, S4, highlighted how it feels to be isolated merely by being in the minority:

Even, I mean I remember when I was attending visual studies class and we were only two black people in my visual studies class...I don't know what you call it but there is a term for it. That all white people, no one is going to notice when you are not in class, but the two black kids - if you are not in class then they will know that you are not there.

Student S4 also highlighted her discomfort with the content of the courses:

I mean you'd see all these pictures about slavery... and other things and people would be so, so like, I mean someone laughs here and laughs there and I'm thinking "What if that were my grandfather or something?"...It was not nice being in those classes. I'm just so glad it's over.

Student S9 mentioned how lecturers were speaking about her and how she didn't have the power to stand up for herself:

[T]hey said...something like, aah you know, this one is struggling but it's to be expected, you know. Maybe she doesn't come from, blah blah blah or something, but it was something mean. I remember and then, did I say something back at her? No, I just hated her after that.

\section{Language and culture}

The culturalisation of racism is often seen through the use of language (De la Rey and Duncan 2003). Since 2016 the language policies of Stellenbosch University have aimed to include English as a medium of instruction. However, the predominance of Afrikaans as a medium of instruction (with interpreting into English) continues to be a source of concern. Language is connected to culture in the South African context. Students' experiences concerning language and culture relate to discrimination they experienced while studying at the Department of Visual Arts. Coloured students who understand Afrikaans and English could feel less othered in this environment than black students who speak another African language and English. It should be noted that Stellenbosch University aims to develop isiXhosa as a third academic language after Afrikaans and English.

Student S6 talked about the discomfort she experienced while attempting to include a non-Afrikaans-speaking student in a conversation:

I have seen how other people have been discriminated against. It makes me feel helpless. Like when myself and another [black] student made some enquiries about bursaries together for post-graduate [studies]... So we went to this lady, for me when someone does not understand Afrikaans, then I speak in English, even if the Afrikaans people laugh at me and stuff. For me it is just about the person not understanding you. Why would you continue speaking in Afrikaans and at a fast pace and so?... Then the more I wanted to speak to the lady in English [to accommodate the student with me], the more she spoke in Afrikaans to me.

Student S3 recalled an incident: 
[The lecturer] was talking Afrikaans when he was criticising my work and then I'd say - I'd tell them, like if you're going to criticise my work then if you do it in English so I can hear you. And then he, he spoke English and then slipped it back to Afrikaans and then I remember me and [name of black student] we left during the crit.

Lecturer L3 recounts an incident during a Student Representative Council (SRC) meeting when a girl asked a question in Xhosa:

[A]fter she asked the question all of us just started applauding her. We were like; yes make your point about the language issue in Stellenbosch, good for you. And then one of the SRC, white, tall, skinny boy answers her in Xhosa and then the applause was even louder...It was just this moment that I think I will never ever forget and I wish that, that was normal.

This student, S7, related her feelings of disjointedness to her own culture:

The way she [a lecturer] spoke to me about my project was almost like, ja, she is a coloured and she lives in the coloured community and she knows more about being coloured than I actually do. Which I was quite offended by, because, I mean, I'm in both positions. I'm an outsider and I'm a coloured myself so I can speak for - I can't speak for [all] coloured people - but I can speak for my community kind of thing. And for her it was just like, ja, she can speak for the coloured people and the coloured community and the academic community all at the same time...

I battled a lot with that project in terms of what coloured identity was all about. I got so frustrated at a time because I was like, being coloured is not about doilies and spices, it's not.

Lecturer L2 explained that language and communication, in a situation where diversity is present, requires negotiation:

The language issue for me has always been like, if there's an area of negotiation, if someone cannot articulate themselves in a certain way then... [we have] to work together and to find ways to communicate. I have my technician who can translate for me in some ways and I have other students who chip in when someone else can't say anything or doesn't have the right words to say something. To that extent there is a process of negotiation.

\section{Economic and social circumstances}

Socio-economic differences between students become apparent in the Department of Visual Arts. Students who do not have access to extra finances have difficulty completing certain assignments. This has a social impact.

This student, S4, shared her feelings regarding economic challenges:

There's... a few individuals who like come from wealthier backgrounds and like obviously their parents will provide. But, for me it's like, aah, I need to think, you know? Maybe I should budget here a little bit and not be too extreme, so [my economic circumstances] did kinda impact me.

Another student, S3, had this to say: 
Definitely the extra expenses [are] a lot. I think it definitely can stop the [creative] process because you will be working and then all of a sudden you'll think "Oh, I need to buy paper" and then you kinda think, well let me put it off for another three days until I pluck up courage to ask my parents.

Finally, this student, S7, summed up her attitude towards economic challenges:

I think that [money] was actually an issue for me, because a lot of the times I couldn't even buy a bottle of thinners. And I mean, I don't look down on that, I understand that, you know? My father was the only one who was working in the whole household and it wasn't even for like millions or whatever...so I understood that asking for money every time for the exhibition was out of the question. And I felt, now looking back on the course, I felt that maybe, if I had more money, I would have gotten higher marks.

\section{Visual hegemony}

Discrimination and "othering" can affect students' creative processes as well as the work they produce.

\section{This student, S2, gave her viewpoint:}

You get this very kinda, similar mindset, where everything is just from their [Afrikaans students'] point of view and then it's a very Afrikaans point of view. It's always from a very privileged position, the art that's made. It's never this real struggle that people are dealing with - poverty and racial issues - which is so prevalent in our country and then you think, well it's an art department. We should be talking about these things.

Student S8 explained how diverse spaces of learning may contribute to the teaching and learning experience:

I've often thought when something like a revolution happened, the only time it was successful was when you threw out a lot of things. It doesn't feel like anything is being thrown out here in Stellenbosch and to a large extent I think the foundations should be shaken a little bit. We get so used to the system that you become so part of it and so relaxed in your own comfort zone.

\section{Student S3 recalled an incident:}

And I remember when, I think it was me and, me and [name of black student], it was a photography project...I was used to be being, like at the bottom, or being the second from at the bottom, and then from like second year things slowly changed and then...I think it was a seventy for a project, for photographic project and then [name of black student], got like an eighty and that. Giving the credit became an, it became an issue. I remember we had a crit...the guy [name of fellow student] was very, he was very mad like "Why did I get like a seventy?"... so he really felt like I didn't deserve that seventy and then also...talked about [name of black student], not deserving that mark that she got. 


\section{DISCUSSION}

The discussion that follows focuses on various issues that arose from the experiences of participants in the Department of Visual Arts of Stellenbosch University. These issues include symbolic racism, language, socio-economic influence, the dominance of Western narratives and the difficulty related to "othering". Symbolic racism results in discomfort for students of colour and stinting of transformation in higher education settings. Transformation is linked to language policies - a contested issue within Stellenbosch University. Language holds political and cultural power. Apart from language, the socioeconomic backgrounds of students also influence their ability to produce academic work and create an imbalance of opportunity among students. An imbalance in the representation of themes is evident in students' work. Western discourses dominate and perspectives are often narrow and exclusive. It remains difficult to discuss "othering" in educational settings, because lecturers may assume that their knowledge of the "other" is superior. Critical citizenship and reflective thinking can be used as tools to address these issues within visual arts learning spaces.

Students mentioned that it was uncomfortable to be students of colour in a class that was predominantly white. This discomfort became especially pronounced in situations where colonialism, apartheid and post-colonialism were taught and discussed. Students felt that in these situations their difference was accentuated, which made them feel more "othered". When people are confronted with situations of discomfort, it could be easier to amalgamate to the environment than to confront the discomfort. In the visual arts, expression plays a key role in learning. If freedom of expression is hampered, the learning process is hindered. Students may feel more comfortable voicing their opinions in their academic writing than discussing their opinions and ideas in an everyday scenario. This discomfort inevitably seeps into their artistic process, which is very reliant on an open and confrontational way of working and discussing their ideas. Symbolic racism causes discomfort for students of colour and allows white hegemony to continue.

Academic requirements help to shield previously white universities from radical racial transformation by using merit to award positions for study. Oloyede (2009) argues that educational practices are used in the process of normalising marginalisation because those accepted into universities are often accepted on the basis of their academic prowess. Ideals of progress and control may allow white academics to negate their role in transformation while perpetuating racism. Discourses of merit allow academics to uphold intellect as the chief concern of universities while transformation, social cohesion and racism receive far less attention. Academics may also disregard pressing issues concerning race, because some universities' internal bureaucracies, which favour white supremacy, have been firmly established (Oloyede 2009). Symbolic racism is practised through a denial of the patterns of racial inequalities that are still prevalent in Stellenbosch University's context. It is also revealed through attitudes and actions of resentment regarding the urgent need for redressing patterns of racial inequalities. As 
a result, antagonism towards certain demands for removing racism exists (Ratele and Duncan 2003).

Part of the way that Stellenbosch University maintains its position of white supremacy, in an evidently changing demographic landscape, is through language. Language plays a major part in upholding elements of symbolic racism in the Department of Visual Arts. Some instruction and communication with peers and lecturers occur exclusively in Afrikaans, even though the university's new language policies promote dual-medium instruction. In recent years, the university has been obligated to address issues of bilingualism and single-language instruction (in English) due to a large influx of English-speaking students. This has caused an array of debates and problems, because some parents and alumni are adamant on maintaining the key role of Afrikaans in the university's language use. Older generations' strong opinions about language policies often filter down to younger generations of students. Language can become an indicator of social change. It has come to represent where progress is evident or where it is hindered (McKinney 2007).

Language signifies systems of power. Symbolic power denotes a system of power that is seemingly invisible and exercised with the involvement of those who are subjected to it yet are unwilling to acknowledge either their role in its implementation or their powerlessness within it. Systems are therefore utilised to enable and ensure the control of one group over another through tools of communication and knowledge (Bourdieu 1991). Language at the university can be used as an agent of control by those in positions of power. The Afrikaans language is tainted with political undertones, because for many black people it is symbolically related to white Afrikanerdom.

Language can also be an indicator of culture. Language links representation to meaning and culture. The representation of meaning allows us to say something significant about how we present ourselves to the world (Hall 1997). At the Department of Visual Arts the majority of the students and lecturing staff are still predominantly white. Those students and staff members who are in the cultural minority in the Department of Visual Arts may need to negotiate their identities in order to avoid cultural isolation. Language conveys meaning in a system of representation that symbolically evokes broader issues of knowledge and power. Foucault (cited in Hall 1997) points to discourse as the production of knowledge through language. Discourse governs the way in which social practices are constructed. Discourse entails both language and practice (Hall 1997).

Social practices in the Department of Visual Arts such as isolation and "otherness" are not limited to racial, cultural and language issues. They encompass a wider social perspective in which the socio-economic context of students must be taken into consideration. The degrees offered at the Department of Visual Arts require extra expenses. A distinction is made between those who can afford these extra costs and those who find it financially difficult to do so. In effect, financial difficulties also bear consequences for the academic work produced. Unequal economic backgrounds create an unfair playing field. Students who suffer in these conditions are often burdened 
with feelings of guilt and shame from continuously asking their parents for money when conditions at home are financially unstable. Imbalances in social and economic circumstances present in the Department of Visual Arts at Stellenbosch University produce a sense of discomfort and pretence.

The focus areas on which students in the Department of Visual Arts choose to concentrate when producing work are of concern. The work produced represents a very narrow worldview. This worldview remains a largely Western one, in which challenging social questions are generally absent. If these issues are addressed, it is often from a very specific perspective that exposes disconnectedness to perspectives outside the students' context. Approximately half of the students at the Department of Visual Arts come from a white Afrikaner heritage. This heritage is a reoccurring theme often studied and researched. Students are encouraged to study their identities and traditions. Students who do not share this particular heritage are also encouraged to look at their own traditions and culture. Many students, however, do not wish to do so because they feel that if they reveal their differing cultural traditions they will be isolated. Menon (2003) argues that artistic styles within a Western rhetoric are seen to be the idealised standard. This standard is seen as the norm that is used to judge other artistic modes that fall outside this ideological perspective.

As we have mentioned before, students have freedom within their artistic work. Yet work produced in a certain institution is influenced by the main discourses taught there. It is within this setting that we would like to argue the following: Stellenbosch University, and especially the Department of Visual Arts, because of its history, has foundations in European ideals that remain influential. It is very difficult to discuss ideas relating to the "other" in this learning space without being burdened by its position in the South African context. In her seminal work "Can the Subaltern Speak?" Spivak (1985) talks about the representations of historical reality. She highlights that "othering" involves an awareness of power, the production of power and the representation of the subordinate. "Othering" takes power away from those being discussed and researched and allows it to be placed into the oppressors' hands to further manipulate the way in which the "other" is viewed and written about. Students in the Department of Visual Arts must therefore rely on knowledge brought across to them by intellectuals who have power over the knowledge being produced in the department. Students from cultures other than the dominant culture present in the department find it difficult to speak about their own traditions and backgrounds. This may be due to the way lecturers assume superior knowledge of these "othered" traditions and heritages. Challenging educational contexts could be mediated by critical citizenship education and reflective thinking.

As Johnson and Morris (2010) suggest, reflective thinking involves a holistic understanding of the context in and around the spaces of learning as well as the relationship between the lecturer and student. To address students' feelings of "otherness", it becomes necessary for lecturers to promote and facilitate learning that is not tied to political motives, but instead nurtured through an understanding and an adoption of reflectivity. This will enable them to have a better understanding of 
the many issues with which students grapple, making it possible to deal with daily complexities that exist within spaces of learning. Combining critical citizenship with reflective thinking enables dialogue between students and lecturers, which is necessary to address issues of "othering" within spaces of learning. This creates a partnership that is vital for pedagogy.

\section{CONCLUSION}

Visual Arts departments are normally considered safe spaces of free expression. In this study it became clear that the creation and maintenance of a "safe" and "free" space of learning require deeper investigation in order to understand the complexities involved. "Othering" because of indirect racism, language or economic circumstances can affect students' creative expression even though the spaces of learning are often considered equal and free.

Participants' experiences reveal the challenges that are deeply rooted in the historical and current narratives of the town in which the university is situated. It also highlights some of the many trials students face with regard to reaffirming their identities in a post-apartheid society. It is difficult to articulate the symbolic racism within the department, because a minority experiences it. And often one only becomes aware of it as an afterthought and in hindsight. As one researcher put it:

You doubt and downplay it as nothing, a mere figment of your imagination. If you call your experience racist you are labelled as too sensitive and calling a race card just for the sake of it. But you feel it, you are always aware of it, you deliberately (well mostly) choose to say and do nothing about it because of the fear of being ridiculed, shamed and causing conflict.

We are of the opinion that addressing the social and economic imbalances within spaces of learning will help address feelings of being "othered" that have been experienced within these spaces. In terms of social and economic circumstances, it is evident from the research that a minority of students experience difficulties. It is our suggestion that, at the start of each project, all students should work with a fixed budget. A suggestion would be that the finances that go towards purchasing materials should be included in the student fees and the same amount should be available to each student at the start of each project. This would not only ensure an equal playing field for students to create work, but would also encourage the development of skills to solve problems creatively through considering materials and working within budget constraints. It may prove to relieve feelings of financial pressure and thereby reduce feelings of being "othered" among students within spaces of learning.

We also suggest that critical citizenship education be expanded within the curriculum at the Department of Visual Arts. It involves processes of critical thinking and critical pedagogy that promote reflective thinking, learning and dialogue. Promoting reflective thinking among lecturers and students would provide lecturers and students with an opportunity better to understand the circumstances in which people find themselves. It 
would also encourage a necessary dialogue between lecturers and students. This dialogue could include students' involvement with creative briefs, surveys and assessment forms that should be filled in by students on a regular basis. Lecturers could become more accessible to students. Students should feel able to voice their opinions freely without fear of the consequences. Improving the dialogue between students and lecturers may enable a relationship founded on a mutual trust necessary for personal growth and growth within post-apartheid spaces of learning.

The data suggest a need for spaces of learning to be more diverse. The implementation of an extended degree programme that allows students from disadvantaged backgrounds an opportunity to enter the degree programme would be a way to address inclusion. A minority of black students does not encourage transformation. We argue that diversity within spaces of learning could contribute to learning experiences that are enriched by knowledge from varying racial backgrounds and perspectives. This would promote a necessary development within the spaces of learning in the Department of Visual Arts of Stellenbosch University.

\section{REFERENCES}

Bignall, S. 2008. "Deleuze and Foucault on Desire and Power." Angelaki 13 (1): 127-47.

Bourdieu, P. 1991. Language and Symbolic Power. Translated by G. Raymond and M. Adamson. Cambridge: Polity Press.

Costandius, E., and S. Rosochacki. 2012. "Educating for a Plural Democratic Citizenship - A Report on Practice." Perspectives in Education 30 (3): 13-20.

Creswell, J. W. 2003. Research Design: Qualitative, Quantitative and Mixed Methods Approaches. London: Sage.

De la Rey, C., and N. Duncan. 2003. "Racism: A Social Psychological Perspective." In Social Psychology: Identities and Relationships, edited by K. Ratele and N. Duncan, 45-66. Cape Town: University of Cape Town Press.

Denscombe, M. 2003. The Good Research Guide. Maidenhead: Open University Press/McGraw-Hill.

Denzin, N., and Y. Lincoln. 2008. Collecting and Interpreting Qualitative Materials. London: Sage.

Garland, J., and N. Chakraborti. 2006. "Race, Space and Place: Examining Identity and Cultures of Exclusion in Rural England." Ethnicities 6 (2): 150-77.

Gillespie, A. 2007. "Collapsing Self/Other Positions: Identification through Differentiation." British Journal of Social Psychology 46 (1): 579-95.

Giroux, H. A. 1992. "Post-Colonial Ruptures and Democratic Possibilities: Multiculturalism as Anti-Racist Pedagogy." Cultural Critique 21 (2): 5-39.

Hall, S. 1985. "Signification, Representation, Ideology: Althusser and the Post-Structuralist Debates." Critical Studies in Mass Communication 2 (2): 91-114.

Hall, S. 1997. Representation: Cultural Representations and Signifying Practices. London: Sage.

Jansen, J. D. 2004. "Race and Education after Ten Years." Perspectives in Education 22 (4): 117-28.

Jensen, S. Q. 2009. "Preliminary Notes on Othering and Agency: Marginalized Young Ethnic Minority Men Negotiating Identity in the Terrain of Otherness." Working paper presented at Castor Seminar Løgstør, 13-14 May, Aalborg University, Aalborg.

Johnson, L., and P. Morris. 2010. "Towards a Framework for Critical Citizenship Education." The Curriculum Journal 21 (1): 77-96.

Klein, H. K., and M. D. Meyers. 1999. "A Set of Principles for Conducting and Evaluating Interpretive Field Studies in Information Systems.” MIS Quarterly 23 (1): 67-93. 
McKinney, C. 2007. "Caught between the 'Old' and the 'New'? Talking about 'Race' in a Post-Apartheid University Classroom." Race, Ethnicity and Education 10 (2): 215-31.

Menon, R. 2003. "Alienation: The Body and Color in Question." Integrative Explorations Journal of Culture and Consciousness 7/8: 197-215.

Odendaal, P. 2012. "Open Letter to Professor Botman, Vice-Chancellor and Rector of Stellenbosch University." http://www.vryestudent.com/profiles/blogs/open-letter-to-professor-botman-vicechancellorand-rector-of1 (accessed October 23, 2015).

Oloyede, O. 2009. "Critical Reflection on the Report of the Ministerial Committee on Transformation, Social Cohesion and the Elimination of Discrimination in Public Higher Education." Perspectives in Education 27 (4): 426-34.

Ratele, K., and N. Duncan, eds. 2003. Social Psychology: Identities and Relationships. Lansdowne: University of Cape Town Press.

Ratele, K., and T. Shefer. 2003. "Bodies and Apartheid." In Social Psychology: Identities and Relationships, edited by K. Ratele and N. Duncan, 88-106. Cape Town: University of Cape Town Press.

Seekings, J. 2008. "The Continuing Salience of Race: Discrimination and Diversity in South Africa." Journal of Contemporary African Studies 26 (1): 1-25.

Spivak, G. C. 1985. "Can the Subaltern Speak?” In Colonial Discourse and Postcolonial Theory, edited by P. Williams and L. Chrisman, 66-111. New York: Columbia University Press.

Staszak, J. F. 2008. “Other/Otherness.” In International Encyclopaedia of Human Geography, edited by N. Thrift and R. Kitchin, 43-7. Amsterdam: Elsevier.

Stellenbosch University. 2011. Institutional Research and Planning. http://sun025.sun.ac.za/portal/page/ portal/Administrative_Divisions/INB/Home (accessed March 12, 2016).

Yin, R. 2009. Case Study Research: Design and Methods. Los Angeles: Sage. 